\title{
Temporary liberties and uncertain futures: young female Muslim perceptions of life in
}

\section{England}

\section{Abstract}

This article explores how young female Muslim university students in London and Birmingham experience life in England. Through focus groups and interviews, talk about three main topics was collected: how young Muslims frame their identities; how they are perceived by others; and how they perceive Muslims to be portrayed and represented in public life. Analysis shows that the participants: presented themselves as ambitious and autonomous; experienced direct and indirect exclusion as young Muslims; perceived a lack of diverse Muslims role models and ambassadors in public life; and that, despite their optimism, felt their futures in Britain were uncertain. The young people recognised the temporary liberties they have around dress and practice as university students that are potentially restricted in wider society. The research highlights the problems created by stigmatising public discourse around Islamist extremism that fuels narrow, deficit-focused policy that exacerbates the exclusion of young Muslims.

Key words: Muslim; young women; exclusion; extremism; identity; policy

\section{Introduction}

Over the last few years, there has been increasing criticism of research, as well as policy and practice, that talks about young Muslims and not with them (Abbas and Awan, 2015; Ahmed, 2015; Alam, 2006; Khan, 2013). This lack of authentic engagement with Muslim communities has led to policy interventions that are problematic for young Muslims (Abbas and Awan, 2015; Coppock and McGovern, 2014; Khan, 2013). In this article, we draw on the 
focus group and interview data from 18 young Muslim women who were university students in England in 2016. We asked participants about their lives, about their own identities and how they feel they are perceived by others, and about media and public representations of Islam. The participants outlined how they were able to exercise their agency to make religious and other choices whilst at university, and many of the young people had spent time reflecting on their faith identity and made choices about the particular practices they were subscribing to. However, they recognised this, at least to an extent, as a temporary freedom. They identified how discourses around extremism led to exclusionary experiences. They also recognised a lack of representation of overtly Muslim people in public life and a tension between certain faith choices and their career prospects. Based on these exclusions and restrictions, they expressed uncertainty over what the future would be like for them in Britain. Despite this, they were ambitious and aspirational.

This article presents an in-depth outline of the findings and themes from our research, framed by relevant literature. The first part of this article explores the relevant literature. We then outline the methods used in our study before presenting the thematic findings from across the data-set. We conclude with some consideration of the implications for policy and practice.

\section{Background}

\section{Problematic discourses vs. individual voices}

The impact of problematic policy and media discourses on young Muslims has been identified in recent studies (e.g., Abbas and Awan, 2015; Ahmed, 2015; Coppock and McGovern, 2014; Khan, 2013). Additionally, the need for more research with them that draws on their own voices and experiences has also been well-established in the literature (cf., Ahmed, 2015; Alam, 2006; Jeldtoft, 2013). This research has shown how problematic discourses present young Muslims as a homogenous and threatening group who need to be 
educated away from extremism and how hearing their individual voices allows their diverse experiences to emerge, as well as highlight the problematic assumptions in public discourse and the impact these assumptions have on their lives.

Khan (2013) is critical of the vast majority of research with Muslim young people, arguing that even where young people's opinions and responses are gathered, the data is interpreted and manipulated by researchers in such a way that their true voices and experiences are lost. He refers to this process as 'theyification'. He argues that public policy has defined the agendas of researchers and funding bodies to the extent that most studies are interpreted to fit with these agendas. Khan identifies how the suspicion among Muslim groups of research and consultation agendas created by this manipulation only exacerbates the lack of their voices in public debate and policy-making. Similarly, Jeldtoft (2013) argues that the 'hyper-visibility' of certain narrow discourses applied to Muslims since 9/11 and the 'war on terror' means that there is little understanding or research into everyday Islam and the everyday lives of Muslims. Jeldtoft argues that the 'othering' discourses remain hyper-visible whilst such everyday experiences remain unknown. Jeldtoft calls for more research that gets beneath the hyper-visible to explore the everyday. Arguably, however, in research with young Muslims, these prominent discourses may emerge anyway as having a significant effect on their everyday lives.

Islamist extremism is currently a key concern in politics, the media and society more widely. An over-emphasis on the threat of extremism in media and policy that is out of proportion with reality has elevated it as a distinct contemporary moral panic. A number of high profile attacks over recent years - and the policy, media and wider responses to these - have arguably exacerbated Islamophobia. The Prevent Strategy, in particular, has been widely criticised for such (Abbas and Awan, 2015; Coppock and McGovern, 2014; Muslim Council of Britain, 2015). Recent Prevent training for those working in public professions, including 
higher education, focuses on encouraging professionals to monitor and report suspected extremist or radicalised young people. Similarly, the UK Government's Counter-Extremism Strategy centres on identifying and preventing radicalization among young people and communities (Home Office, 2015). Whilst other forms of extremism are given token attention, such as neo-Nazism, the Strategy is particularly concerned with Islamist extremism. These policy discourses are stigmatizing of Muslim young people and communities.

Research with young Muslims suggests that public discourse can make it difficult for them to negotiate their identities as British Muslims. For example, Ahmed (2015) found that young British Muslims often feel they are being asked to choose between being British or Muslim. She found that young Muslims face a particularly challenging context for their identity formation, against a public backdrop of constant questioning of their loyalty, citizenship and integration. Policy understandings and definitions of citizenship in Britain in relation to young people also have been consistently narrow for the last two decades. Under New Labour, for example, the notion of 'active citizenship' was largely focused on young people's economic conformity and on volunteering (see, for example, Transforming Youth Work 2002, Youth Matters 2005). More recently, citizenship policy and pedagogy have been increasingly oriented towards young people's conformity to 'British values', directly in response to the rising fear of radicalisation (as in the Counter-Extremism Strategy 2015).

Similarly, policy understandings of citizenship have been found to be problematic in other multicultural, secular societies. In Australia, for example, Roose and Harris (2015) argue that an over-emphasis on securitisation and the 'management' of Muslim communities has led to policies based on the narrow assumption that young Muslims need to become more engaged in positive citizenship activities. Their research with young Muslims found that these young 
people are already engaging in 'self-driven' activism in secular civic spaces and that flawed policy around multiculturalism and integration has completely overlooked this.

The prevention of extremism discourse is problematic in that enhances Islamophobia and stigma, and may even be counterproductive (Brown and Saeed, 2015; van den Bos et al, 2013; Yilmaz, 2016; Pentazis and Pemberton, 2009). This deficit-focused and stigmatising discourse impacts on young Muslims at a time of their developing and negotiating identities (Abbas and Awan, 2015; Ahmed, 2015; Brown and Saeed, 2015) and may even increase their susceptibility to radicalisation (Ahmed, 2015; van den Bos et al, 2013; Yilmaz, 2016). van den Bos et al (2013), for example, found through research with young Dutch Muslims, that vulnerability to radicalisation involves three key factors; these being, a sense of injustice, a feeling of group threat, and self-doubt. Similarly, in the UK, Ahmed (2015) found that some young Muslims recognize that modern foreign policy, particularly discourses surrounding the 'war on terror', lead to feelings of disenfranchisement and exclusion. She states: 'One participant added, that in the search for identity and belonging, "had it not been for prointegration groups such as the Islamic Society of Britain, I could have been attracted the easier [more absolute] message of an extremist group"' (Ahmed, 2015: 45). She suggests that, rather than reinforce such disenfranchisement, policy and practice interventions need to support young Muslims to negotiate healthy identities against this difficult backdrop. However, making simplistic links between young people feeling challenged and their vulnerability to radicalisation may be problematic in itself (Githens-Mazer, 2012) and more work is needed in identifying how Muslim young people are affected by the negative discourses about them.

\section{Identity Formation and Education}


Similar to Ahmed (2015), Davies (2009) has argued that identity formation is complex for young Muslims. Davies (2009) suggests that a critical education in political and media literacy needs to be provided in school for young Muslims. At the same time, Ahmed (2015) argues that the culture of questioning they face means that young Muslims are often more politically literate than their peers. She outlines how they struggle to have their voices heard on contemporary issues affecting them and that they may be dismissed as disloyal or 'unBritish'. She argues that over the last two decades, young British Muslims have faced increasing levels of stigma and stereotyping. This stigma is reinforced by problematic preventative educational interventions.

Current policy drives deficit-focused interventions by practitioners and educators (Stanley and Guru, 2015; Sukarieh and Tannock, 2016). There is a need for an alternative, more positive and less stigmatising approach to citizenship and identity education in schools and community settings than these deficit focused-models allow for (Abbas and Awan, 2015; Stanley and Guru, 2015). Community-based practitioners and formal educators can be at the forefront of challenging problematic assumptions and developing more empowering interventions (Abbas and Awan, 2015; Stanley and Guru, 2015). Sukarieh and Tannock (2016), for example, have suggested that practitioners need to develop more transformative and positive learning experiences than the deficit-focused approach that centres on antiradicalisation allows for. In Canadian research, Eidoo (2016) found that young Muslim women were developing their own community-based and after-school spaces in which they took refuge from Islamophobia and racism, as well as from cultural patriarchal restrictions, and developing their own forms of learning, community and citizenship.

As well as this clear need for more positive educational models for citizenship and identity development, both Pels and de Ruyter (2012) and Sukarieh and Tannock (2016) argue that there is a gap in knowledge and evidence as to the impact and effectiveness of the current 
deficit-focused educational interventions in preventing radicalisation. As explored here, however, recent research with young Muslims suggests that such policy and practice interventions do create stigma (Ahmed, 2015; Abbas and Awan, 2015; Coppock and McGovern, 2014; Stanley and Guru, 2015).

\section{Higher Education as the site of study}

Higher Education Institutions (HEIs) are particularly important sites of self-identity formation and therefore particularly important as sites of research in the experiences of young Muslims. In small-scale research with Pakistani and Bangladeshi young women at university in England, Ghaffar (2017) found that her participants were aspirational. However, responding to the fact that the transition from university to graduate employment is lower for Bangladeshi and Pakistani young women than for other students, she found that the young women engaged in what she refers to as 'defensive othering' (Ghaffar, 2017). As such, they distanced themselves from the stereotypes they perceived of Asian women as passive and unambitious, but rather than challenging them, framed themselves as individual exceptions. Ghaffar (2017) suggests that there is a 'cultural class ceiling' for Pakistani and Bangladeshi young women, both in attending university and transitioning from undergraduate study into employment. Similarly, the Social Mobility Commission (in research which Ghaffar has been involved with), found that young Muslims face more economic disadvantage than any other group and that educational success does not translate into comparable employment outcomes (Stevenson et al, 2017).

HEIs may also be important spaces in religious identity formation for young Muslims. Possamai et al (2016) argue that universities are post-secular spaces in which public expression of religiosity is tolerated and in which there are largely positive attitudes towards diversity. In their large-scale survey research in Australia, they found that Muslim students 
were confident to practice their religion as university students. They found that they were very unlikely to 'lose faith' at university and that their faith may be enhanced. There was some variation in this with Muslim students tending to become more secularised at city universities and more religious in regional HEIs. The majority of their participants did claim to have experienced discrimination in educational settings but for most of them this was a rare occurrence. They also found that the positive attitudes towards diversity among university students helped enable the Muslim students to develop a resilience to discrimination.

HEIs can also be seen as sites of perceived negative religious identity formation, particularly in terms of radicalisation. In the UK, Brown and Saeed (2015) recognise that policy (through the Prevent Strategy) has developed recent interventions to specifically monitor potentially 'radical' groups and individuals at universities. This follows from a number of 'radicalised' individuals being found to have become so whilst in higher education. Brown and Saeed found that young Muslims' potential for activism at university is constrained by such interventions as well as impacting on their identities and experiences more widely. This suggests that the criticisms of educational interventions outlined above extend to higher education and leaves open the question of the lived experience of young Muslims in light of these.

\section{Individualisation and structure}

As well as living the majority of their lives in the post-911 context, the current generation of young Muslims have grown up in a society that offers unique challenges to young people more widely. Young people today have lived only through the neo-liberal era in which individual responsibility is emphasised and structural issues disregarded. This context will 
have impacted on how young Muslims negotiate their responses to public discourse and Islamophobia.

Furlong and Cartmel (2007) draw on the work of Beck (1992) and Giddens (1991) to outline how young people growing up after the 1980s are living in era where insecurity and risk are the norm, and where transitions (such as those around education, employment and housing) have become more precarious and elongated for emerging adults today. The uncertainty and precariousness of these transitions is exacerbated by the fact the risks are new and not experienced by previous generations. O'Connor (2014) outlines how within this 'risk society', as characterised by Beck (1992) and Giddens (1991), there is a focus on individualisation whilst, alongside this, relationships have become dis-embedded from the local context and are informed by global changes and events. Young people then negotiate the challenges and opportunities of these global events in their everyday lives with a focus on their own individual responsibility. For young Muslims growing up in the post 9/11 context, the challenges of this arguably become acute after terrorist events as well as being an ongoing backdrop to their lives. The global, public discourse of Islam as a threat pervades their choices and transitions including those around education and employment.

Furlong and Cartmel (2007) explore the growth of risky and precarious employment, housing and other transitions alongside the focus on individual responsibility. They outline how this means that young people are negotiating their identities in a context in which insecurity and uncertainty are prevalent and in which the burden is on the agency of the individual to navigate and overcome these risks. They are critical of Beck's (1992) claim that class boundaries have become blurred (recognising the nuance of his argument around the greater risks still being carried by those with less wealth and privilege) and argue that structural inequalities have become obscured rather than less pervasive. 
Some scholars have critiqued the over-emphasis on young people's choice and agency in contemporary sociological research arguing that a return is needed to a recognition of how structural factors such as class, gender and ethnicity shape their lives (Brannen and Nilsen, 2005; Furlong and Cartmel, 2007). Others have argued that Beck's work has been interpreted too simplistically and is not about occupying a 'middle ground' between structure and agency (Woodman, 2009; Farrugia, 2013). What these various scholars tend to agree on is that rather than such inequalities having become less significant, young people often simply do not see these structural factors because they have grown up in the era of individualisation, where their agency and reflexivity is emphasised over structural factors.

In research in a Canadian 'boom-town', O'Connor (2015) found that differences in the intersections of class, gender, and ethnicity determine whether young people recognise how these structural factors shape their lives. For example, the aboriginal young people in their research were able to identify structural inequalities relating to ethnicity, and young women in the labour market were able to see those shaped by gender. He argues that "social structures have not necessarily become obscured equally for everyone in late modernity" (O’Connor, 2015: 878), demonstrating that even a view that social inequalities have become obscured through individualisation is too simplistic an understanding.

For young Muslims growing up in the post-911 context, their experience is likely to be a unique one where individualisation and pervasive negative public discourse about Islam affects how they negotiate and frame their identities and perceptions of responsibility. A recent report from the Social Mobility Commission on outcomes for young Muslims found that they face barriers, in comparison to their peers, in achieving social and economic outcomes through a lack of social, cultural and financial resources (Stevenson et al, 2017). This included the transition from education to work. The young Muslims involved in the 
research were able to articulate these barriers, including discrimination and lack of resources, at least to an extent, thus suggesting they may be aware of the structural issues that affect their lives.

\section{Methodology}

\section{Research question and objectives}

This study aimed to address the following question:

What are the perspectives of young Muslim students in Birmingham and London on what it is like to be young and Muslim in Britain today?

The objectives within this were:

- To explore what it is like to be young and Muslim in Britain today;

- To explore specifically the experiences of Muslim university students in London and Birmingham;

- To explore how young Muslims deal with multiple identities such as British, Muslim, student - and how their faith informs or conflicts with these identities;

- To explore these issues from the perspectives of young Muslims themselves;

- To examine whether moral panics around radicalisation and the responses to it emerge as significant in the participants' lives.

In exploring this question and objectives, we are keen to emphasise that young Muslims in Britain are not a homogenous group and that the responses included individual perspectives and experiences with some common themes rather than findings that can be generalised to the entire Muslim-student population in Britain, or indeed, even in the cities in which we located our study. The findings serve to emphasise the impact that the current policy and media 
context in particular is having on the lives of some young people and there are implications for policy and practice to be drawn from this. We are keen to emphasise here that we did not directly ask the young people about radicalisation or extremism. However, the significance of these public discourses emerged in their responses.

\section{Sample and Method}

The participants for the study were recruited from two small post-1992 universities, ${ }^{1}$ one in Birmingham and one in London. A large proportion of students at these universities are from the local area and live at home while they study. London and Birmingham are the UK's first and second largest cities, both with high Muslim populations from diverse ethnic and religious backgrounds, ranging from long-settled to newly-arrived.

In total, 19 students took part: 18 female and one male. This was, at least in part, because the students were from university departments that tend to be female-dominated, these being Education and Social Work. Whilst calls for participants did go beyond these departments through email to student email addresses and through flyers posted around the universities, students who took part were largely those from the departments in which the researchers (who were known to them) were based. The calls for participants invited students who identified as Muslim to take part in research about their experiences at university and more widely. Participants were all aged between 18 and 25 years old, and self-identified as Muslim.

The intended method for the study was focus groups and students were encouraged to attend focus groups in their friendship groups. We encouraged them to attend in their friendship groups because we wanted to hear talk between themselves rather than simply between them and the researcher and were aware that discussion of personal experiences might be stilted with strangers. Two students chose to take part in one-to-one interviews instead. In total, five 
focus groups (of between one and one and a half hours) and two interviews (of around 40-45 minutes) took place. The focus groups and interviews took place in small seminar rooms in the universities.

The students who took part were all British and from Asian or African ethnic backgrounds, primarily Pakistani, Bangladeshi and Somali. The focus groups contained students from a mix of these backgrounds despite being based on friendship groups. The students tended to form their focus groups with friends from their course of study.

Ethics approval for the research was obtained from both universities. Participants were informed of their right to withdraw from the study at any point and assured of their confidentiality and anonymity protections. The questions were phrased to allow participants to elaborate uninterrupted. Following an initial discussion-starting exercise, the questions were open questions to allow for extended answers and ensure that participants were able to follow a collective conversation, with as little interference from the researchers as possible. The questions focused on asking them about:

- The significant features of their own identity

- The perceptions they think others have of them

- What it means to them to be Muslim

- Any situations in which they have felt particularly visible as a Muslim

- How Muslims are portrayed in the media

- How they see their future

We began the focus groups and interviews with an exercise adapted from Dehanas (2013) involving the young people picking identity labels for themselves. In Dehanas's research, he 
offered several labels to participants to choose from and rank according how far they identified with them. We chose to leave the labels blank and we asked our participants to identify five labels they would attribute to themselves and five labels they felt that others apply to them. This exercise was effective at starting the discussions around the first two questions outlined above.

\section{Analysis}

We analysed our data drawing on principles of Interpretative Phenomenological Analysis (IPA) as outlined by Smith et al (2009). IPA was an appropriate analytical method for several reasons. Most particularly, it is designed to be used with small samples with in-depth analysis of a low number of cases. Therefore, it is appropriate for a project that wants to hear individual voices rather than develop grand generalisations. IPA draws out themes within as well as across transcripts focusing on the individual cases as much, if not more so, as the cross-cutting themes that span the data-set.

Another benefit of using IPA is that it addresses the position and interpretations of researcher in that it sees such interpretation and analysis as the researcher's relationship with the data. This was important because the team were largely non-Muslim researchers. The analysis in IPA takes account of the positionality of researcher to participants. In particular, our analysis drew on how this affected stories told or language used; for example, where participants used the word 'headscarf' rather than 'hijab' or framed their stories in certain ways because they were addressing non-Muslims. This became most apparent in how some of the young women downplayed discrimination or Islamophobia, or responsibilised themselves, even after discussing the more explicit examples of it.

The researchers engaged in two analysis 'workshops' as well as completing further analysis before and after these events. Each transcript was analysed firstly by identifying initial 
comments, then exploratory questions, before identifying themes within the transcript. This analysis of individual cases was then built on to identify themes that occurred across the dataset. This article focuses on some of the themes that occur most frequently both within and across the individual responses of the 18 young women who took part in the research. Research with young Muslims has been criticised for its over-analysis and its manipulation to the agendas of public discourse (Khan, 2013). Therefore, in this article we have aimed to avoid over-analysing the experiences of our participants but to dedicate the vast majority of it to simply presenting their stories and to letting these speak for themselves. An additional level of analysis was done, focusing on the linguistic qualities of the narrative positioning particularly in the stories of lived experience (Authors, in press).

\section{Findings}

Four major themes emerged as significant within the individual responses of the 18 young women and across the dataset. These are:

- Autonomy and ambition

- Experiences of exclusion

- Absence of Muslims in public life

- Uncertain Futures

\section{Autonomy and ambition}

During the exercise in which we asked the participants to identify labels that reflected their identity, several of the young women chose at least one label relating to their autonomy and aspirations. These included, among others: independent; ambitious; feisty; motivated; liberated; confident; and focussed. Being a 'student' was also a significant part of their identity for most of them. Many were keen to emphasise that they had ambitions for their 
future that they saw themselves as having the agency to fulfil. One young women stated, for example: 'I would say I am focussed with want I want with life and in regards to that I am hard working so I know what I want and I am working towards it'. Several of participants ranked their identity as a student above their identity as Muslim, contrasting with similar research with young Muslims which has found they see themselves as 'Muslim first' (such as that by Dehanas 2013 in a similar exercise where students chose pre-written labels from ethnic and religious categories). Without our offering prepared labels for the participants to choose from, a small number of the participants didn't choose religious or ethnic labels at all and a small number did not write Muslim on any of their five identity labels. Among those that did, a few of them qualified it, for example writing 'British Muslim' or 'modern Muslim', suggesting a diversity in how participants self-identified, without being given a clear directive.

Several of the participants focused on their identity as the first generation in their families to go to university and that they saw themselves as role models to younger family members, particularly female, as in the following extract:

I do I feel like I am a role model to my younger siblings because I think hard work really does pay off and I am somebody who like, when I think about it, if you look in my family I am like the only girl who has been to university, like in my wider family and for them that is a big thing. (Participant, London)

However, the emphasis on autonomy and aspirations was rooted in a recognition of the restrictions some young Muslim women face particularly outside of Britain. In framing these restrictions, our participants emphasised a distinction between religious and cultural traditions as in the example below. 
I think sometimes people twist religion with culture, and that is the danger because some cultures are quite anti-education because they are quite anti-liberal in a lot of ways and I think that's kind of where the confusion comes from. (Participant, London)

This understanding of autonomy, however, included some tension. One participant, for example, offered a nuanced articulation of how having autonomy, education and a career was not in conflict with her nor her family's understanding of Islam. Then, when discussing why she had not been allowed by her family to travel, after her brother had been allowed to visit several countries of his choosing, she justified this as an understandable safety issue and her, as female, as less safe.

\section{Experiences of exclusion}

The young people all had stories of exclusion that related to their being Muslim and these were more intensified after 'terror attacks'. At the time that we conducted our research in the first half of 2016, the most recent high profile Islamist terror attack had been the attacks in Paris, France, in November 2015, in which over 130 people were killed in multiple shootings and bombings targeted several public places including the Bataclan concert venue. The young people were not asked specifically about these attacks, nor about any terrorist attack, but their feelings of exclusion after such events emerged from their discussions in focus groups. Many of these moments were indirect; times in which they felt rather than explicitly experienced exclusion, as in the example below.

I was going on placement recently when the Paris attack happened, I used to take the Hammersmith and City line from my house and it is like a lot of business people on there, you know, like everyone is suited and booted and like it's packed and I've noticed that like several times there is a seat next to me but people don't want to sit 
down, and I'm like I always think like maybe I am exaggerating and then I see sometimes people picking up their bag and try and like excuse themselves and it's like in a place they can't even fit and I'm like 'ok, why is this?' And when someone else gets up from a place then everyone rushes to it and I'm like 'there's a seat right next to me!' (Participant, London)

As in the example above, these feelings of exclusion were often experienced in subtle rather than extreme ways. The participants' responses suggested that after terrorist events, moments of exclusion were clearly more frequent and sustained, with public transport a common space in which these moments occurred. While some of the participants did not describe experiences of direct exclusion, many had friends or family who had and they reported these events as having a deep effect on them. These experiences included both physical attacks, such as family or friends being assaulted in the street or having headscarves forcibly removed, and verbal accusations made by strangers. One participant in Birmingham described an encounter her friend had on the bus shortly after the terrorist attack in Paris in November 2015. Her friend had recounted to her an experience of getting on a busy bus where a white woman was sitting down with her bag on the otherwise empty seat next to her. When the participant's friend asked the woman to move her bag so that she could sit down, the woman had refused. The woman then confronted her aggressively, referring to the recent Paris attacks and stating that 'it was because of her this had all happened'. The young women expressed feeling the impact of such situations even when hearing about them happening to friends or family rather than them happening directly to them. In this case, the participant concluded 'Even though that didn't happen directly to me I felt we are getting discriminated against'.

Prejudice experienced by others was reported as adding to the overall sense of exclusion among many of the participants. Whilst the most direct and more extreme experiences of 
exclusion were less frequent, they did happen, such as for the young woman below who was reflecting back on the aftermath of the London attacks in July 2005 when she was eleven years old.

After 7/7 I was in Year 6 and during the line up to go into school before the bell, and this guy, and he was my friend sort of, and he came running up around shouting ' $\mathrm{Oh}$ you've got a bomb, you've got a bomb!' (Participant, London)

Whilst this accusation came from a friend, other experiences of such direct exclusion came from strangers. For example, one young woman's experience of having someone shout 'you terrorist' out of a car window as they passed her and other participants in their encounters with people on public transport, in shops or on the street. However, in the focus group setting, the participants often sought to make light of such experiences, frequently laughing about them and discussing them with some humour. One young woman, for example, pointed out during a focus group how someone not sitting next to her co-participant on the tube was rather futile if she was indeed going to 'blow up the whole carriage'. Where they had faced these exclusionary situations or confrontations with friends or classmates, they were keen not to accuse them of discrimination stating, for example: 'I wouldn't accuse them of Islamophobia'. Yet, the combination of regular, subtle experiences and less frequent explicit experiences of direct exclusion, as well as the awareness of moments of discrimination experienced by others, added to an overall reported sense of marginalisation for the young people who felt both fearful themselves and that they were the object of others' fear.

The young women who dressed in ways that made it obvious they were Muslim felt exclusion most strongly. This was couched in the knowledge that their dress made them stand out as 'different', and most particularly as non-British. 
With everything going on, sometimes they won't explicitly say but they would imply like 'problematic', like a foreigner kind of thing... You just get that look like you don't conform to the way a British citizen looks because you wear a headscarf. (Participant, Birmingham)

Again, it is significant that these experiences were often felt rather than explicitly experienced in the form of a direct attack or accusation. However, there was a clear link between dress and the likelihood of being perceived as an extremist across the responses. This was often discussed following the exercise in which we asked them to identify labels that they felt others put on them. One young woman responded as such:

Well for me I think Hijab - terrorist - Muslim - extremist... Some people have that view because of influences like the media, because obviously I wear a headscarf, the long clothes. Some people might think my get up is sort of one [laughs] that makes me an extremist. (Participant, Birmingham)

Given the majority of terror attacks that have received high profile coverage in Britain have not involved female perpetrators it is interesting that such explicitly female religious dress features so strongly in their sense of marginalisation and of being seen as suspicious. The overwhelming majority of these experiences of exclusion faced by the young people related to them being identifiable as Muslim. Only once did one participant explain a scenario in which it had related to ethnicity when a group of young people on the bus had shouted 'get off the bus, Asians' to her and a friend when they were on placement in a part of Birmingham with which they were unfamiliar.

\section{Absence of Muslims in public life}

The young women were acutely aware of a lack of representation of Muslims in public life, particularly in media and politics. They noted recent exceptions to this such as Nadiya 
Hussain winning the Great British Bake-off in 2015 and Sadiq Khan being elected as London Mayor during 2016 whilst we were undertaking this research. However, they very much saw these examples as exceptions and emphasised that they could not possibly represent all Muslims nor that all Muslims could relate to them. One London participant outlined how unlikely it is to encounter people in traditional Muslim dress on television or in public-facing industries.

I think it would be very strange if you saw a man in a beard with a hat and like what I am wearing on the $\mathrm{BBC}$ like as a regular person... I do feel like in certain industries if you want to go far you have to like really dilute something because like in mainstream if you were to, erm yeah do that, and if you want to stay who you are then you are quite limited in your options. Like for example my friend with the face veil, I think like in terms of employment she is, like, there is a lot of barriers to where she can work because a lot of people wouldn't accept somebody who was hiding their face and if it's like customer services, for example, you can't quite like hide your face so I think like how you dress and your views will definitely obstruct you from entering certain places or accessing certain kind of careers. (Participant, London)

The young women were also particularly aware that the more explicitly they appeared Muslim in how they chose to dress or in following certain practices, the more likely they were to struggle in finding employment. One young woman in London discussed the dilemma for her friend who wants to become a teacher but who currently chooses to cover her face. The participants recognised they had a freedom at university that they may not encounter in wider society. Several of the participants had, during their time at university made conscious decisions relating to their dress and practice; for example, to wear the hijab, to stop serving alcohol while working for the student union, and to not shake hands with males. However, they recognised these choices as temporary liberties that they may have to 
forego if they chose to enter certain professions after graduation. Choosing to engage in these practices had been an expression of their autonomy as they explored their faith identities as young adults, and not traditions imposed upon them by others as is too often assumed.

Whilst those young women in London who were interviewed after Sadiq Khan's election as Mayor in May 2016 recognised this as a potentially positive step for Muslims, they were tentative to celebrate. Two young women in one focus group discussed how vitriolic the campaign against him had been. They commented on the fact that he is a Muslim who dresses and acts particularly 'moderately'. They discussed being aware that some very conservative religious groups had previously issued a Fatwa on him for 'voting in favour of gay marriage' and contrasted this with their observations of him being accused of being an Islamist Extremist during the Mayoral campaigns. These accusations towards someone they identified as particularly 'moderate' led to them having little hope for more diverse representations of Islam to be incorporated into public life.

The participants discussed that more prominent Muslims were able to gain significant profiles on YouTube and through other social media channels. The young women at a focus group in London outlined how they felt more able to relate to these informal role models than those examples in public life. However, they recognised that these role models are 'separate from the mainstream' and that their influence and representation is largely limited to within young Muslim online communities and not beyond.

\section{Uncertain Futures}

The research took place in March and April of 2016, the months preceding the Brexit vote and during the early stages of Donald Trump's US Presidential campaign. The anti-Muslim rhetoric that follows terror attacks and that was being politicised and utilised in these 
campaigns contributed to a fear for the future among the young people. Some questioned whether there was a future for them in Britain at all.

It is going to be awful, it is going to be scary, I am scared for our children in this society. If I could I would move back to Pakistan. With Pakistan it is just simple, everyone gets along no matter what, there is no disrespect and everyone treats each other equally, but you get to England and it is just the media and stuff like that, you just get fed up of it. So, I think it is just really grim. (Participant, Birmingham)

Some of the participants expressed fear for younger siblings or future children growing up in Britain. However, despite their fears and the exclusion they felt, Britain was 'home' and not somewhere they imagined leaving.

I think the way that things are now, it could either escalate to the extent that it is going to be hard for Muslims but it could also improve as well. I don't think I would move away from Britain. I would stay here because it is where I was brought up. (Participant, Birmingham)

This was also reflected in the initial 'identity labels' exercise where many of them chose to include British as a key feature of their identity. Despite recounting negative experiences as outlined in the sections above, the young people's views of the future were not unanimously nor entirely negative. Many expressed hope that things would improve. One participant described society as 'progressive' and expressed her belief that, in the long-term, things have gotten better over time and will continue to do so. In a London focus group, one participant suggested 'it would be worse in America' for Muslims. The young women in this group felt that discrimination against Muslims was worse in the US than Britain, particularly with reference to Donald Trump's mounting presidential campaign. 
Finally, the participants also expressed a desire to do what they could to make things better, as in the example below.

I am going to try my best as an independent Islamic woman like all these lot to stick up for myself and stick up for my family name and stuff and stick up for my religion and try and make it a better place. (Participant, Birmingham)

Several of the young women described a sense of personal responsibility to change things; to help others understand Muslims better and to counter negative assumptions. This was couched in a sense of others not always being to blame for their assumptions, particularly where the young people had been confronted by friends or classmates. These responses suggest that the participants were acutely aware of the power of public discourses about them, reflecting Ahmed's (2015) assertion that young Muslims have a high level of political literacy, borne from this struggle with public discourse. It refutes Davies (2009) notion that young Muslims need to be better taught such political literacy. Rather than this being framed as an education issue (as by Davies), there is arguably a need to understand and respond to the impacts of the pressure that young British Muslims feel to counter negative perceptions and misunderstandings. This, again, reflects Ahmed's (2015) research where she argues that young Muslims face a potentially overwhelming sense of responsibility to dispel negative discourses and to represent British Islam as positive at an age at which their own identity formation is taking place.

\section{Implications}

The young women who took part in the focus groups were ambitious and aspirational, but the responses suggest that the university was a site of temporary liberties where the young people can make autonomous religious choices. The participants were largely unaware of increased monitoring for radicalisation at universities brought in with recent Prevent guidance and did 
not appear to experience the constraints that Brown and Saeed (2015) identified in their research. The young people had made conscious choices around their dress and practice whilst at university, as part of their wider identity formation. They recognised, however, that there were restrictions to this in wider society and after graduation, particularly in relation to their career prospects.

These responses reflect Possamai et al's (2016) research in Australia which found universities to be tolerant post-secular spaces in which diversity is embraced. The fact that this tolerance was not felt to exist in wider society, particularly in public life, set potential limits on the young people's autonomy. The problematic transition from university into graduate careers for Asian young women (Ghaffar, 2016) could be, at least partially, linked with this intolerance in wider society and the lack of diverse role models in public life identified by our participants. However, the focus of Ghaffar's research is ethnicity rather than religion and so the overall issues differ. For example, the 'defensive othering' that Ghaffar identified among Pakistani and Bangladeshi young women did not occur for our participants. Whilst Ghaffar's participants portrayed themselves as exceptions to the cultural stereotypes they identified about Asian women, our participants felt a responsibility to counter negative assumptions about Islam. They were also keen to emphasise that being ambitious was compatible with their faith. It is arguable that the young women in our research were able to identify, at least to an extent, the structural issues they faced in their experiences of exclusion because of the pervasiveness of negative public discourse about Islam. They were therefore less likely to engage in 'defensive othering' and present themselves as exceptions to a norm. Instead, they were able to challenge such norms. Research from the Social Mobility Commission also found that young Muslims tend to want to defend Islam rather than distance themselves from it when encountering negative stereotypes (Stevenson et al, 2017). 
Negative public discourses clearly have an impact on young Muslims and lead to exclusionary experiences as identified both through our research and that of others. Jeldtoft (2013) criticises the research that focuses on the problematic and hyper-visible discourses of Islam and has called for more research into the everyday lives and practices of Muslim communities. It is significant here, that although we did not directly ask our participants about radicalisation or extremism, the impact of these discourses on their everyday lives emerged as highly significant, particularly when participants linked their own or others' experiences of discrimination, harassment, or exclusion to these discourses.

A policy and practice response is needed which add to a growing body of literature that highlights the problems created for young Muslims by deficit-focused and stigmatising policies and interventions (Abbas and Awan, 2015; Ahmed, 2015; Coppock and McGovern, 2014; Khan, 2013). The implications of this have international applicability as stigma and Islamophobia have increased in other contexts too. Our participants were particularly fearful for Muslim young people in America where right-wing anti-Muslim rhetoric has gained a powerful platform. The research discussed earlier from Australia and Canada suggests Muslim young people face similar struggles with the stigma created by public discourse (Eidoo, 2016; Roose and Harris, 2015).

\section{Individualisation versus structural discrimination}

The young women in our research arguably have dual forces at work on their lives. They have lived all but the early years of their lives in the post-911 context and thus are unable to personally remember a time before negative public discourse about Islam was hyper-visible.

They have also grown up in the climate of neoliberalism where individual responsibility is emphasised. This leads them to, at times, see Islamophobia as a problem for them to fix themselves, as evidenced by their reluctance to blame friends or acquaintances who held 
problematic assumptions about them. Instead, they spoke about being a better representative of Islam and responsibilised themselves to "stick up for myself and stick up for my family name and stuff and stick up for my religion and try and make it a better place”.

However, the forces of individual responsibility and persistent exclusion are in tension. This is seen in the young women's uncertainty about the future and yet sense of themselves as autonomous and ambitious, as well in the sense of their freedom experienced at university as temporary or limited. In discussing future careers, they recognised barriers but spoke about a choice whether to continue wearing certain dress or practising in certain ways rather than about challenging the systems that exclude them.

Young Muslims are thus a unique group of young people negotiating identity and agency in a climate of individualisation and Islamophobia - both of which are persistent realities of their lives. Because of the hyper-visibility of negative public discourse and the exclusionary experiences they face, both ongoing and intensified at certain times, certain structural issues are visible to them as they negotiate their identities and experience the perceptions others have of them. However, they both identify the structural barriers and see themselves as responsible to change or overcome them. The visible Islamic identity of our participants is an additional intersection not faced by other groups of young women. This visible religious identity fits alongside their gender, ethnicity and age to shape unique challenges in their lives. Their experience reflects the research by O'Connor (2015) that social structures are not equally obscured for all young people. Yet, a sense of individual responsibility emerges in their discussion of how change might be effected.

\section{Conclusion}

This article has shown how fear of accusation and even violence, as well as an ongoing sense of marginalisation, affect the lives of young Muslims. The young people in our research were 
acutely aware that they were objects of fear, as well as being fearful themselves of the exclusion they face, both direct and indirect. Yet, they also maintained a sense of hope and of humour in discussing their experiences and were often keen not to accuse people of discrimination and Islamophobia and to take some responsibility for challenging stigma. They both identified the structural exclusion they face and saw themselves as responsible for challenging or overcoming it. Problematic policy, such as Prevent and the CounterExtremism Strategy in the UK, arguably affect young Muslims in a disproportionately negative way, as do the vitriolic media campaigns that follow Islamist terrorist attacks. A level of proportionality is needed in such media and policy discourses rather than them being fuelled, or indeed fuelling, the moral panics that result in the exclusion of and prejudice towards young Muslim people.

Those working with young people need to challenge this structural exclusion where they see it and aim to work positively with young people, bringing them together and working with their assets and potential. The boycotting of Prevent funding by many grassroots organisations is a justifiable refusal to work with problematic and stigmatising policy discourses. There is a need to change the way policy and practice interventions are framed so that they do not target young Muslims as a potential threat. Instead, there is a need to combat the stigma and exclusion these young people face. In addition, further understanding is needed of the impact of the pressure that young Muslims face to defend Islam whilst still forming their own identities. More diverse representation of Islam and of Muslims is needed in public life such as politics and the media where our participants felt there was a dearth of role models and ambassadors they could relate to.

\section{Acknowledgement}


This research was funded by XXX department at XXX University.

\section{References}

Abbas, T. and Awan, I. (2015) Limits of UK Counterterrorism Policy and its Implications for Islamophobia. International Journal for Crime, Justice \& Social Democracy 4(3): 16- 29.

Ahmed, S. (2015) 'The Voices of Young British Muslims: Identity, Belonging and

Citizenship' in Smith, M. K.; Stanton, N. and Wylie, T. (Eds.) Youth Work and Faith:

Debates, Delights and Dilemmas, Lyme Regis: Russell House.

Alam, M. Y. (2006) Made in Bradford, Pontefract: Route Publishing.

van den Bos, K., Doosje, B. and Loseman, A. (2013). Determinants of Radicalization of Islamic Youth in the Netherlands: Personal Uncertainty, Perceived Injustice, and Perceived Group Threat. Journal of Social Issues 69 (3), 586-604. http://dx.doi.org/10.1111/josi.12030.

Beck, U. 1992. Risk Society: Towards a New Modernity. Thousand Oaks, CA: Sage.Brannen, J., and Nilsen, A. (2005) 'Individualisation, Choice and Structure: A Discussion of Current Trends in Sociological Analysis.' The Sociological Review 53 (3): 412-428.

Brown, K. E. and Saeed, T. (2015) Radicalization and counterradicalization at British universities: Muslim encounters and alternatives, Ethnic and Racial Studies, 38:11, 19521968, DOI: 10.1080/01419870.2014.911343.

Cohen, S. (1972) Folk Devils and Moral Panics, London: MacGibbon and Keeohen.

Coppock, V. and McGovern, M. (2014) 'Dangerous Minds'? Deconstructing CounterTerrorism Discourse, Radicalisation and the 'Psychological Vulnerability' of Muslim Children and Young People in Britain. Children \& Society 28 (3): 242-256. 
Davies, L. (2009) Educating against Extremism: Towards a Critical Politicisation of Young People. International Review of Education, 55 (2):183-203.

Dehanas, D. N. (2013) Elastic Orthodoxy: The Tactics of Young Muslim Identity in the East End of London. In Dessing, N. M, Jeldtoft, N., Nielson, J. S. and Woodhead, L. (Eds.) Everyday Lived Islam in Europe. London: Ashgate.

Eidoo, S. (2016) Pedagogies of Muslim feminisms: reflections on faith, space and citizenship, Gender and Education, DOI: 10.1080/09540253.2016.1225016.

Farrugia, D. (2013) 'Young People and Structural Inequality: Beyond the Middle Ground.' Journal of Youth Studies 16 (5): 679-693.

Furlong, A. and Cartmel, F. (2007) Young People and Social Change: New Perspectives. Maidenhead: Open University Press.

Ghaffar, F. (2016) 'Supporting the progression of Pakistani and Bangladeshi girls into higher education'. Conference presentation at 'Widening Participation Together: Achievements of National Networks for Collaborative Outreach'. London: 16/11/16.

Ghaffar, F. (2017) 'Defensive othering: theorising British Pakistani and Bangladeshi women's strategies and constructions of self-identity within higher education and the labour market'. Research poster available at: https://www.offa.org.uk/uncategorized/wideningparticipation-research-projects-progress/\#othering.

Giddens, A. (1991) Modernity and Self Identity: Self and Society in the Late Modern Age. Stanford, CA: Stanford University Press.

Githens-Mazer, J. (2012). The rhetoric and reality: Radicalization and political discourse. International Political Science Review, 33(5): 556-567.

Home Office (2015) Counter-Extremism Strategy. London: Crown copyright. 
Muslim Council of Britain (2015) Concerns on Prevent, available at:

http://www.mcb.org.uk/wp-content/uploads/2015/10/20150803-Case-studies-about-

Prevent.pdf.

Jeldtoft, N. (2013) The Hyper-visibility of Islam. In Dessing, N. M, Jeldtoft, N., Nielson, J. S. and Woodhead, L. (Eds.) Everyday Lived Islam in Europe. London: Ashgate.

Khan, M. G. (2013) Young Muslims, Pedagogy and Islam, Bristol: Policy Press.

O’Connor, C. D. (2015) 'Classed, raced, and gendered biographies: Young people’s understandings of social structures in a boomtown'. Journal of Youth Studies. 18(7): 867-883.

O’Connor, C. D. (2014) 'Agency and reflexivity in boomtown transitions: Young people deciding on a school and work direction'. Journal of Education and Work. 27(4): 372-391.

Pantazis, C. and Pemberton, S. (2009) From the 'Old' to the 'New' Suspect

Community: Examining the Impacts of Recent UK Counter-Terrorist Legislation. British Journal of Criminology 49 (5): 646-666 doi: 10.1093/bjc/azp031.

Pels, T. and de Ruyter, D. J. (2012). The Influence of Education and Socialization on Radicalization: An Exploration of Theoretical Presumptions and Empirical Research. Child \& Youth Care Forum, 41(3), 311-325. http://doi.org/10.1007/s10566-011-9155-5.

Pihlaja, S. and Thompson, N. (2017) "I love the Queen”: Positioning in young British Muslim discourse. Discourse, Context and Media, 20, pp.52-58.

Possamai, A., Dunn, K., Hopkins, P., Worthington L. and Amin, F. (2016) Muslim students' cultural and religious experiences in city, suburban and regional university campuses in NSW, Australia, Journal of Higher Education Policy and Management, DOI: 10.1080/1360080X.2016.1211950. 
Roose, J. M. and Harris, A. (2015) Muslim citizenship in everyday Australian civic spaces, Journal of intercultural studies, 36 (4): 468-486.

Smith, J. A., Flowers, P. and Larkin, M. (2009) Interpretative Phenomenological Analysis, London: Sage.

Stanley, T. and Guru, S. (2015) Childhood Radicalisation Risk: An Emerging Practice Issue, Practice, 27:5, 353-366, DOI: 10.1080/09503153.2015.1053858.

Stevenson, J.; Demack, S.; Stiell, B.; Abdi, M.; Clarkson, L; Ghaffar, F.; Hassan, S. (2017)

The Social Mobility Challenges faced by Young Muslims. London: Social Mobility Commission.

Sukarieh, M. and Tannock, S. (2016) The deradicalisation of education: terror, youth and the assault on learning. Race \& Class 57 (4), 22-38.

Woodman, D. (2009) 'The Mysterious Case of the Pervasive Choice Biography: Ulrich Beck, Structure/agency, and the Middling State of Theory in the Sociology of Youth.' Journal of Youth Studies 12 (3): 243-256.

Yilmaz, I. (2016) Socio-Economic, Political and Theological Deprivations' Role in the Radicalization of the British Muslim Youth: The Case of Hizb ut-Tahrir. European Journal of Economic and Political Studies 2 (1), 89-101.

\footnotetext{
${ }^{1}$ Post-1992 universities are former polytechnic colleges that have gained university status since this became possible in 1992. Before gaining university status, these colleges offered higher education programmes validated by another university. Their focus was on programmes with a technical, vocational or professional focus.
} 